${ }^{1}$ Growth and Development Department, Ajman University, United Arab Emirates.
Corresponding author: Dr. Afraa Salah Hussain Ajman University Department of growth and development United Arab Emirates/Ajman POX: 364 /UAE

Phone: 009716-747-2222

Email: a.salah@ajman.ac.ae

Received: October 04, 2019

Accepted: May 02, 2020

\section{Knowledge of tooth avulsion first aid management among parents residing in UAE}

\author{
Afraa Hussain ${ }^{1, *}$, Raghad Hashim $^{1}$ iD , Aisha Khamees ${ }^{1}$
}

Aim: This study aimed to evaluate the knowledge of parents visiting a specialized dental center in Ajman on permanent tooth avulsion and the required first aid procedure to achieve better prognoses. Methods: A cross-sectional study was conducted in Ajman Emirate, UAE. Three hundred eighty-eight parents from three nationalities (Emirati, Egyptian and Indian) residing in UAE answered a constructed questionnaire that included demographic information related to the participants and questions related to permanent tooth avulsion and the required first steps for its management. Results: Study findings reflect deficiencies in the following areas. Of the 388 parents, $(236,60.8 \%)$ had poor knowledge about permanent tooth avulsion. Parents who had previous knowledge obtained information from unsupported sources, such as friends $(145,37.4 \%)$. Out of 388 parents, $(324$, and $83.5 \%)$ would not replant the tooth. Finally, the majority of the participants did not know the proper media to store the avulsed permanent tooth with one-third of parents choosing cotton or water (142, $36.6 \%)$. Conclusion: This study showed a lack of knowledge regarding permanent tooth avulsion among parents from the major nationalities residing in UAE. However, the respondents represent major differences regarding related to knowledge, replant, and storage of avulsed permanent teeth.

Keywords: Ethnic groups. Knowledge. Parents. Tooth. Tooth avulsion. 


\section{Introduction}

Dental trauma is one of the common types of accidents that children may experience during their primary and mixed dentitions stages ${ }^{1}$. Dental trauma may range from crown fracture to complete removal of the tooth out of its socket ${ }^{2}$. Permanent tooth avulsion is the complete removal of a primary or permanent anterior or posterior tooth out of its socket because of trauma or accident ${ }^{2,3}$. The major scenes of dental trauma include school and home; the most common reasons for permanent tooth dental trauma are falling, accidents, fights, and sports involving physical activities ${ }^{3}$.

Implantation of an avulsed tooth is positively related to the immediate and accurate management of the avulsed permanent tooth 4 . Epidemiological studies showed that parents and school nurses are generally responsible for the primary management of an avulsed permanent tooth; however, their knowledge that the avulsed tooth should be maintained, cleaned and stored in proper media was inappropriate and insufficient ${ }^{4,5}$.

An avulsed permanent tooth requires certain first aid steps to keep the tooth in good condition until a specialist in a dental center replants the tooth. These steps include tooth cleaning with running water without surface scratching and maintaining the tooth in proper storage media, such as saline, milk or saliva to prevent dehydration and surface cell death ${ }^{6}$. Tap water was unacceptable storage media for avulsed tooth since it will cause PDL cell damage due to the low osmolarity of tap water?

The necessary steps to save the avulsed permanent tooth are commonly known among dental team members; however, epidemiological studies showed that nonprofessionals (parents, caregivers, school teachers) are not aware of information regarding the immediate steps needed to save an avulsed permanent tooth ${ }^{4,5}$.

Immediate management of an avulsed permanent tooth requires important steps to keep the tooth in a proper condition until replanted into the socket by dental professionals. Many studies represented the poor or absence of parents' knowledge about the option of keeping the tooth and bringing it with the child to the dental center for replantation. Some studies presented different failure percentages in saving the avulsed permanent tooth due to the caregiver's failure to take action to save the tooth ${ }^{8,9}$. Caregivers did not know that the permanent avulsed tooth should not be out of the socket for more than 30 minutes for a good prognosis ${ }^{5,10}$. Other studies found that caregivers were unaware of the transport media for avulsed permanent tooth storage until the dental center was reached ${ }^{9}$. In addition to being unaware of information regarding cleaning and holding, information on how to properly treat the avulsed permanent tooth was also lacking ${ }^{3,6}$. The United Arab Emirates has a wide diversity. However, the three major nationalities residing in UAE are Indian (37\%), Emirati (20\%), and Egyptian $(12 \%)^{8}$.

The purpose of this study is to evaluate parents' knowledge from three nationalities residing in the UAE regarding emergency management of permanent avulsed teeth. 


\section{Materials and Methods}

\section{Study design and population}

This cross-sectional study was conducted for a period of 4 months (August 2018 to November 2018). The participants were recruited from parents who accompanied their children attending Ajman university dental specialized center for dental treatment. The institutional ethical committee approved the study (Ref. GD - 2018/6 - 11). G*Power version 3.1.9.2 software was used to calculate the sample size. The effect size was calculated based on $80 \%$ power and a significance level of $a=0.05$ in which $30 \%$ of parents could not demonstrate any knowledge of the emergency management of dental avulsion. The minimum sample size was 350: however, an additional $20 \%$ was added to compensate for the expected drop out of the study. Thus, a total sample size of 420 was selected. A total of 388 randomly selected parents participated in this study. Parents from (Emirati, Egypt, and India) were recruited randomly and parents from other nationalities were not included in this study. Questionnaire evaluation was pretested on 30 parents attending the medical center where certain words were changed for more clarification of the questions. Participants from this pilot study were excluded from the main study.

\section{Study questionnaire}

The study questionnaire was constructed based on a literature review of previously used questionnaires related to the topic of permanent teeth avulsion. The questionnaire was designed to include two parts. The first part represents demographic information of the parents, including gender, age, level of education, and nationality. The second part includes questions related to parents' assessment of their knowledge and attitude as well as emergency management of the avulsed permanent tooth. The researcher provided the questionnaire in English and Arabic (the local language in UAE) for Arab and non-Arab parents. A pilot study was conducted as a preliminary study to identify any grammar or technical problems.

\section{Questions}

The first part of the questionnaire represented parents' demographic information in the following order: sex as male and female; age categorized into five categories (20-30), (30<- 40), (40<- 50), (50<- 60), and (60<); and parents' nationality categorized into three scales: (Emirates), (Egyptian), (Indian).

The second part of the questionnaire includes the following questions: do you have any information regarding dental trauma Do you have any information about tooth avulsion? What are the sources of your information? What action did you take when your child experienced trauma that resulted in permanent tooth avulsion? What action would you take if your child had an avulsed primary tooth? What action would you take if your child had an avulsed permanent tooth? What would you do with the avulsed permanent tooth? What action would you take with a dirty avulsed tooth? What would you do to clean an avulsed tooth?

Did you replant the avulsed tooth? How would you handle the avulsed tooth? What storage media would you use for an avulsed permanent tooth? 


\section{Statistical analysis}

Data analysis performed using Statistical Package for Social Science software version 22.0. Recorded data tabulated and expressed by using a descriptive analysis test to get the required frequencies and percentages of participant's respondents.

\section{Results}

\section{Demographic information}

Study participants consisted of 272 (70.1\%) women and $116(29.9 \%)$ men. The majority of the participants were in the (30-40) age range (44.3\%). Out of 388 participants, $215(55.4 \%)$ had a university degree. In total, 182 (46.9\%) of the participants were of Egyptian nationality followed by Indian nationality 110 (28.4) and Emirati nationality 96(24.7). Details on the demographic information presented in Table 1.

Table 1. Sociodemographic characteristics of the parents $(n=388)$.

\begin{tabular}{|c|c|c|c|}
\hline \multirow{2}{*}{ Characterestics } & \multirow{2}{*}{ Variables } & Frequency & Percentages \\
\hline & & $\mathrm{N}$ & $\%$ \\
\hline \multirow{2}{*}{ Sex } & male & 116 & 29.9 \\
\hline & Female & 272 & 70.1 \\
\hline \multirow{4}{*}{ Age } & $20-30$ & 105 & 27.1 \\
\hline & $31-40$ & 172 & 44.3 \\
\hline & $41-50$ & 85 & 21.9 \\
\hline & $51-60$ & 26 & 6.7 \\
\hline \multirow{7}{*}{ Level of education } & non educated & 2 & 0.5 \\
\hline & Primary & 20 & 5.2 \\
\hline & Mid-school & 28 & 7.2 \\
\hline & High -school & 99 & 25.5 \\
\hline & College & 215 & 55.4 \\
\hline & Master & 23 & 5.9 \\
\hline & Phd & 1 & 0.3 \\
\hline \multirow{3}{*}{ Nationalities } & Egyptian & 182 & 28.4 \\
\hline & Indian & 110 & 46.9 \\
\hline & Emirates & 96 & 24.7 \\
\hline
\end{tabular}

\section{Dental knowledge}

The percentage of the parents who had previous information about tooth avulsion was $152(39.2 \%)$. However, the majority of parents $(236,60.8 \%)$ felt they had inadequate information about traumatic dental injuries.100 (26\%) Egyptian parents, 70 (18\%) Emirati parents, 66(17\%) Indian parents (Figure 1). 


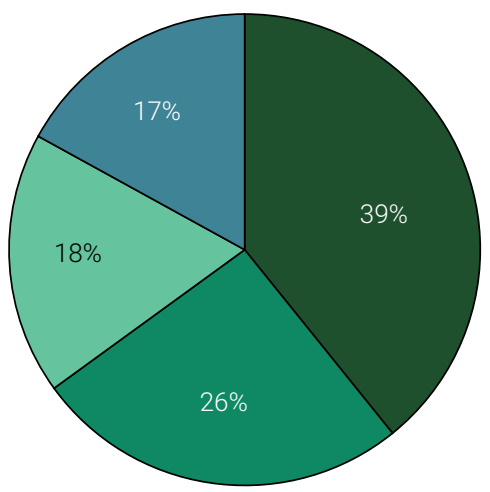

Parents with dental knowledge

$\square$ Emirati parents

$\square$ Egyption parents

Indian parents

Figure 1. Dental Knowledge among parents residing in UAE

\section{Knowledge sources}

Regarding the source of the information (if they had any previous information), more than one-third of the parents reported that they received information from friends $(145,37.4 \%)$. In total, $90(23.2 \%)$ of Indian parents received information from a physician. $80(20.6 \%)$ of Emirati parents obtained information from a dentist. Finally, 73(18.8\%) of Egyptian parents received information from the internet. (Figure 2)

Sources of Dental Knowledge

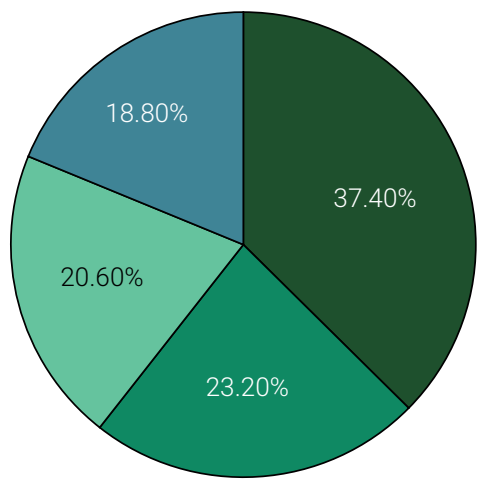

Friends

Emarati parents (Dentist)
Indian parents (physician)

Egyption Parents (Social media)

Figure 2. Sources of dental knowledge 


\section{Tooth replantation}

Out of 388, only 64 (16.5\%) of the respondents reported that they would replant an avulsed permanent tooth in its socket. However, the majority $83.5 \%(n=324)$ of the respondents said they would not replant it. 170 (41.3\%) Egyptian parents, 80 (19.4\%) Emirati parents, 94(22.8\%) Indian parents (Figure 3).

Tooth replant reluctance

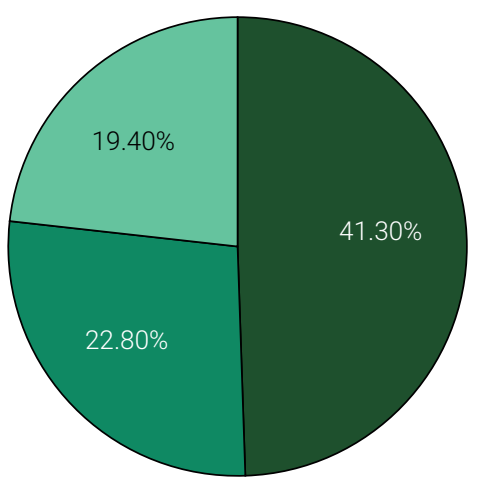

$\square$ Egyption parents

$\square$ Indian parents

$\square$ Emarati parents

Figure 3. Tooth replant reluctance

\section{Types of media for avulsed tooth storage}

Regarding the media for storing an avulsed permanent tooth until reaching the dentist, Indian parents 101(26\%) chose no physiological media (paper tissue). Egyptian parents 142 (36.7\%) chose cotton or water. Emirati parents chose milk 85(21.9\%). $60(15.4 \%)$ of the three nationalities chose more than two options (Figure 4).

Types of prefered storage media

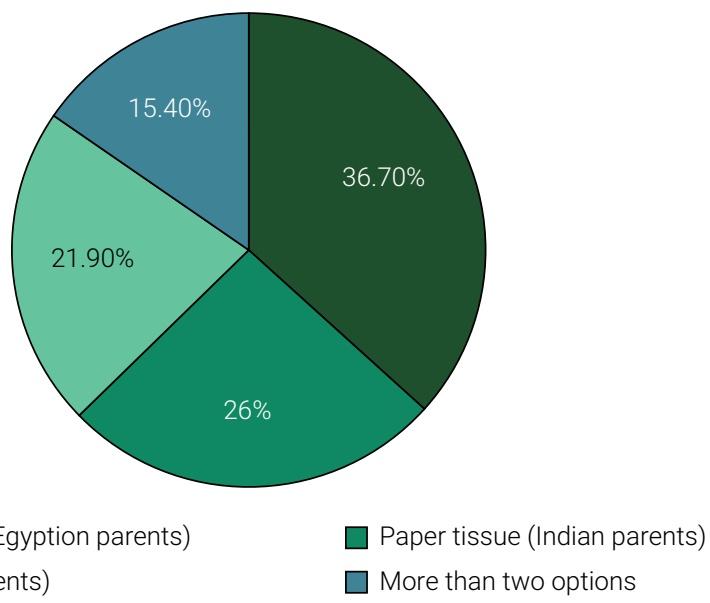

Figure 4. types of storage media for avulsed tooth 


\section{Discussion}

Children play activities that are highly susceptible to dental trauma ${ }^{7}$. Permanent Tooth avulsion is the only critical dental condition where unprofessional individuals (parents, caregivers, and schoolteachers) who were present at the accident area performed immediate action 9 . In this study, the majority of the respondents (60.8) from the three nationalities revealed that they lack adequate information regarding permanent tooth avulsion conditions and proper management. However, Egyptian parents showed higher percentages. This finding was similar to other studies in different countries, such as Kuwait, Jordan, Brazil, Tehran, and Hong Kong ${ }^{1-5}$.

This unfortunate finding indicates the lack of dental health knowledge among people, which should be managed by lectures and brochures through different channels, such as schools, universities, media, and meetings ${ }^{6}$.

This study showed that sources of required management of permanent tooth avulsion received from different channels; however, this information could be incorrect or missing important issues necessary for tooth prognosis. Most Indian and Emirati parents of the study respondents received their knowledge on permanent tooth avulsion from physicians and dentists (23.2\% and 20.6\%, respectively). However, they realized that the information was improper or adequate to help provide action at the accident scene. This finding similar to the finding of another study in India that suggested that physicians and dentists should provide an adequate and serious explanation of such knowledge to people through preventive measures or workshops ${ }^{8}$. One-third of parents get their knowledge from friends (37.4\%), which represents a social source for this issue. A study in Egypt showed a similar finding that necessitates the presence of leaflets and posters to increase individual awareness through community channels ${ }^{11}$.

The final source of information in this study was the internet, which was cited by Egyptian parents $(18.8 \%)$ higher than other respondents. This finding was similar to previous studies where the internet represents a powerful source for different issues; however, a high percentage of incorrect knowledge could be found on the internet especially for nonprofessionals ${ }^{1,4}$. High expenses of dental treatment and lack of dental insurance are the major causes of the absence of dental visits of the residents in UAE which affect their meeting with the dentists to had the correct information from the correct source.

The majority of our respondents in this study would not replant a primary or permanent avulsed tooth (83.5\%). The higher percentages were among Egyptian parents (41.3\%). This major finding was consistent with the results of previous studies in India ${ }^{12,13}$, Turkey ${ }^{9}$, Egypt, and Kuwait1,10,11.

This finding could be attributed to the fact that the majority of people who do not have any information about the required first aid to replant an avulsed permanent tooth could not perform any procedure at the time of the accident. Such a finding acts as an alarm to the responsible specialty to provide necessary information through numerous channels.

Regarding storage media selection for an avulsed permanent tooth, the respondents reported different opinions. Indian parents chose paper tissue as a temporary stor- 
age media for the avulsed tooth $(26.0 \%)$. This finding was similar to previous studies in India ${ }^{14,15}$. Emirates Respondents chose milk (21.9\%). This finding is consistent with many previous articles; however, the responses exhibited different percentages ${ }^{11,16,17}$. Egyptian respondents replied with tap water or cotton as storage media for the avulsed permanent tooth (36.7\%). This finding is similar to Egyptian parents' responses regarding avulsed tooth storage media ${ }^{11}$.

The general findings of this study revealed a lack of information regarding permanent tooth avulsion and the required necessary steps and precautions to be considered when the parents were responsible for the required action. Different responses could be related to different cultures, which affect people's attitudes towards health conditions and their management. Important steps required to increase community awareness regarding immediate management of tooth avulsion through many channels like social media, schools, medical centers, and hospitals ${ }^{18}$.

In conclusion, this study showed that Egyptian parents need more dental awareness regarding dental conditions. Indian and Egyptian parents did not receive dental knowledge from the dentist due to the higher cost of dental treatment. Egyptian nationality represents the higher percentage of parents' refusal to replant avulsed teeth. Emirati parents had the best knowledge in storing the avulsed tooth in the best media.

\section{Highlights of the Study}

Dental trauma is an important clinical condition in dentistry. Children may experience dental trauma during their first years of life and mixed dentition stages. Most dental trauma conditions receive treatment in a dental clinic. However, permanent tooth avulsion requires first aid procedures at the trauma location before final treatment in a dental clinic. The background knowledge of nonprofessional individuals on the required first aid steps to store an avulsed permanent tooth is critical.

\section{Acknowledgement}

This study accomplished by the help of the dental general practitioners Dr. Fatima Abbas, Dr. Hanan AlBannaai and Dr. Latifa AlSaeed in questionnaire distribution and collection.

Statement of Ethics:This study was approved by the ethical committee of Ajman university.

Disclosure Statement: The authors have no conflicts of interest to declare.

Funding Sources: This research is self-funded.

\section{References}

1. Alyahya L, Alkandari SA, Alajmi S, Alyahya A. Knowledge and sociodemographic determinants of emergency management of dental avulsion among parents in Kuwait: a cross-sectional study. Med Princ Pract. 2018;27(1):55-60. doi: 10.1159/000486095.

2. Al-Jundi SH. Knowledge of Jordanian mothers with regards to emergency management of dental trauma. Dent Traumatol. 2006 Dec;22(6):291-5. doi: 10.1111/j.1600-9657.2005.00371.x. 
3. Ahlawat B, Sharma A, Kaur A, Chaudhary N, Sharma S, Kumar A. Tooth avulsion: its perspective among athletically active children of Chandigarh, India. J Oral Res Rev. 2016 Jan;8(1):12-5. doi: 10.4103/2249-4987.182494.

4. Hashim R. Investigation of mothers' knowledge of dental trauma management in United Arab Emirates. Eur Arch Paediatr Dent. 2012 Apr;13(2):83-6. doi: 10.1007/BF03262849.

5. Chan AW, Wong TK, Cheung GS. Lay knowledge of physical education teachers about the emergency management of dental trauma in Hong Kong. Dent Traumatol. 2001 Apr;17(2):77-85. doi: 10.1034/j.1600-9657.2001.017002077.x.

6. Al-Asfour A, Andersson L. The effect of a leaflet given to parents for first aid measures after tooth avulsion. Dent Traumatol. 2008 Oct;24(5):515-21. doi: 10.1111/j.1600-9657.2008.00651.x.

7. Bazmi BA, Singh AK, Kar S, Mubtasum H. Storage media for avulsed tooth - a review. Indian J Multidiscip Dent. 2013 May;3(3):741-9.

8. Population of UAE.Global Review of the Implementation of the Fundamental Principles of Official Statistics. 2018.

9. Qazi SR, Nasir KS. First-aid knowledge about tooth avulsion among dentists, doctors and lay people. 2009 Jun;25(3):295-9. doi: 10.1111/j.1600-9657.2009.00782.x.

10. Shashikiran ND, Reddy VV, Nagaveni NB. Knowledge and attitude of 2,000 parents (urban and rural - 1,000 each) with regard to avulsed permanent incisors and their emergency management, in and around Davangere. J Indian Soc Pedod Prev Dent. 2006 Sep;24(3):116-21. doi: 10.4103/0970-4388.27891.

11. Loo TJ, Gurunathan D, Somasundaram S. Knowledge and attitude of parents with regard to avulsed permanent tooth of their children and their emergency management--Chennai. J Indian Soc Pedod Prev Dent. 2014 Apr-Jun;32(2):97-107. doi: 10.4103/0970-4388.130781.

12. Namdev R, Jindal A, Bhargava S, Bakshi L, Verma R, Beniwal D. Awareness of emergency management of dental trauma. Contemp Clin Dent. 2014 Oct;5(4):507-13. doi: 10.4103/0976237X.142820.

13. Ozer S, Yilmaz El, Bayrak S, Tunc ES. Parental knowledge and attitudes regarding the emergency treatment of avulsed permanent teeth. Eur J Dent. 2012 Oct;6(4):370-5.

14. Nikam AP, Kathariya MD, Chopra K, Gupta A, Kathariya R. Knowledge and attitude of parents/ caretakers toward management of avulsed tooth in Maharashtrian population: a questionnaire method. J Int Oral Health. 2014 Sep-Oct;6(5):1-4.

15. Marino TG, West LA, Liewehr FR, Mailhot JM, Buxton TB, Runner RR, et al. Determination of periodontal ligament cell viability in long shelf-life milk. J Endod. 2000 Dec;26(12):699-702. doi: 10.1097/00004770-200012000-00005.

16. Holan G, Shmueli Y. Knowledge of physicians in hospital emergency rooms in Israel on their role in cases of avulsion of permanent incisors. Int J Paediatr Dent. 2003 Jan;13(1):13-9. doi: 10.1046/j.1365-263x.2003.00414.x.

17. Young C, Wong KY, Cheung LK. The effectiveness of educational poster on knowledge of emergency management of dental trauma - part 2: cluster randomized controlled trial for secondary school students. PLoS One. 2014 Aug 5;9(8):e101972. doi: 10.1371/journal.pone.0101972.

18. American Academy of Pediatric Dentistry. Guidelines on management of acute dental trauma. Pediatric Dentistry Reference Manual 2012-13;34:230-8. 


\section{(Appendix-1)}

Patients Attending AUST (From August 2018 - November2018)

Gender: Male Female

Age:

1. 20 - 30 years

2. 31 - 40 years

3. 41 - 50 years

4. 51 - 60 years

5. $>60$ years

\section{Level of Education:}

1. Not Educated

2. Primary

3. Middle School

4. High school

5. College

6. Master

7. PHD

\section{Nationality:}

1. Emirates

2. Egypt

3. India

\section{Questionnaire:}

*avulsed tooth $=$ Fallen by an accident or trauma

\section{Choose the appropriate answer:}

1. Have any of your children had dental trauma?

- Yes, had trauma other than tooth avulsion.

- Yes, had avulsed primary tooth

- Yes, had avulsed permanent tooth

- No, had not 
2. Do you have any previous information about tooth Avulsion?

- Yes

- No

3. If you had such information, what is the source of that information:

- Dentist

- Physician

- Media

- Friends

4. If your child has an avulsed primary tooth, what will you do?

- Searching to find the tooth

- Not searching for it

5. If you would find the primary tooth, what will you do?

- Replant the tooth

- Not replanting it

6. If your child have an avulsed permanent tooth, you will:

- Search to find the tooth.

- Not searching for the tooth.

7. If you would find the permanent tooth, what will you do?

- Replant the tooth

- Not replanting it

\section{If you would search for the tooth, please complete the following questions:}

8. If you found the tooth covered with dirt, what will you do?

- Clean the tooth then save it

- Save the tooth only

- Replant the tooth

- I don't know

9. If you would clean the tooth, you will use:

- Tooth brush

- Tap water

- Antiseptics

- I don't know 
10. If you would replant the tooth, you will do that:

-Immediately

- Within half an hour

- At any time

11. You will handle the avulsed tooth from:

- Crown

- Root

- Either

12. If you will transport the avulsed tooth to the dentist, you will use:

- paper tissue

- Cotton

- Tap water

- Milk

- I don't know 